\title{
Vaccination with Mage-b DNA induces CD8 T-cell responses at young but not old age in mice with metastatic breast cancer
}

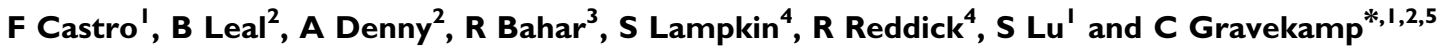 \\ 'California Pacific Medical Center Research Institute, 475 Brannan Street, San Francisco, CA 94 107, USA; ${ }^{2}$ Department of Cellular and Structural Biology, \\ University of Texas Health Science Center San Antonio, 15355 Lambda Drive, San Antonio, TX 78245, USA; ${ }^{3}$ Department of Physiology, University of \\ Texas Health Science Center San Antonio, I 5355 Lambda Drive, San Antonio, TX 78245, USA; ${ }^{4}$ Department of Pathology, University of Texas Health \\ Science Center San Antonio, 7703 Floyd Curl Drive, San Antonio, TX 78229, USA
}

BACKGROUND: Elderly individuals react less efficiently to vaccines than do adults, mainly because of T-cell unresponsiveness. In this study, we analysed whether tumour-associated antigen (TAA)-specific CD8 T-cell responses could be induced by vaccination in old mice with metastatic breast cancer.

METHODS: The effect of pCDNA-3. I - and Listeria-based vaccines, expressing TAA Mage-b, on Mage-b-specific immune responses was tested in spleens and draining lymph nodes (LNs) of mild $(4 \mathrm{TO} 7 \mathrm{cg})$ and aggressive $(4 \mathrm{TI})$ syngeneic metastatic mouse breast tumour models at young (3 months) and old (20 months) age.

RESULTS: Interferon $\gamma$ and interleukin-2 levels increased significantly in draining LNs and spleens of Mage-b-vaccinated mice compared with those in control groups at young but not old age in both mouse tumour models. A significant increase was observed in the number of IFN $\gamma$-producing Mage-b-specific CD8 T cells after Mage-b vaccination in the 4TI model at young but not old age. This correlated with a reduced protective effect of Mage-b vaccination against metastatic breast cancer at old compared with young age. CONCLUSIONS: The absence of CD8 T-cell responses after Mage-b vaccination and the accompanying reduced protection against metastatic breast cancer in old compared with young mice point towards the need for tailoring cancer vaccination to older age. British Journal of Cancer (2009) I 01, 1329- 1337. doi:I0.1038/sj.bjc.6605329 www.bjcancer.com

Published online 29 September 2009

(c) 2009 Cancer Research UK

Keywords: old age; young age; breast cancer; metastases; Mage-b DNA vaccine; innate immune system

Elderly women have much higher breast cancer incidence and mortality rates than do young women. As demographic trends indicate that over the next few decades the number of elderly women will increase substantially, strategies for breast cancer prevention and therapy need to be optimised to older patients. Current treatment options for localised breast cancer include surgical resection of primary tumour, assessment of regional lymph nodes (LNs) and removal, if positive, followed by adjuvant chemotherapy or hormonal therapy (Scarth et al, 2002). Cancer vaccines are less toxic than chemotherapy or radiation and could, therefore, be especially useful for elderly, often frail patients. However, it has been reported that elderly individuals react less efficiently to flu and pneumococcal vaccines than do younger adults, because of T-cell unresponsiveness (McElhaney et al, 1994; Quyang et al, 2000). Therefore, research is required to establish whether age-specific tumour immunological variables permit the

*Correspondence: Dr C Gravekamp, Department of Microbiology and Immunology, Albert Einstein College of Medicine, 1300 Morris Park Avenue, Forchheimer Bldg, Room 407A, Bronx, NY I046I, USA; E-mail: cgraveka@aecom.yu.edu

${ }^{5}$ Current address: Department of Microbiology and Immunology, Albert Einstein College of Medicine, 1300 Morris Park Avenue, Bronx, NY 1046I, USA.

Revised 20 August 2009; accepted 24 August 2009; published online 29 September 2009 optimal use of cancer vaccines for the prevention and therapy of cancer in the elderly.

Thus far, all cancer vaccines used in clinical trials have only been tested in preclinical models at young age. However, more recent data demonstrate that age is an important factor for the efficacy of cancer vaccines. For instance, Provinciali et al (2003) showed that immunisation with a pCMVneuNT DNA vaccine was effective in young but not old mice bearing neu-expressing breast tumours. This correlated with high levels of anti-neu antibodies induced by the vaccine in young but not in old mice. Lustgarten et al (2004) showed that immunisation with a pre-B-lymphoma cell line (BM-185) expressing GFP and CD80 (B7.1) induced longlasting immune responses and tumour rejection of wild-type BM185 tumours at young but not old age. However, when coadministered with anti-OX-40 mAbs, vigorous long-lasting immune responses and tumour rejection were observed at both young and old age. A similar effect of anti-OX40 was observed in a syngeneic prostate cancer model at young and old age (Sharma et al, 2006). A conclusion that can be drawn from these studies is that none of the vaccines were effective at older age, but that tailoring the vaccines to older age seems feasible.

In this study, we analysed the effects of vaccination in preclinical mouse tumour models of metastatic breast cancer at young and old age. In contrast to primary tumour, metastases cannot be removed by surgery or radiation, and most metastases are chemoresistant (Pardal et al, 2003). Thus, metastases and not primary tumours are 
the most important contributor to breast cancer morbidity and mortality. To study the efficacy of cancer vaccination against breast cancer metastases, two different preclinical metastatic breast tumour models were used, that is, $4 \mathrm{TO} 7 \mathrm{cg}$, which is a relatively mild model with 2-20 metastases per mouse, and the much more aggressive 4T1 with 5-300 metastases per mouse. Both models highly express Mage-b tumour-associated antigen (TAA) in their primary tumours and metastases (Gravekamp et al, 2004, 2008). Mouse Mage-b is homologous to human MAGE-B (Lurquin et al, 1997). MAGE antigens are particularly interesting for the development of breast cancer vaccines, because their expression (MAGE-A and MAGE-B) has been frequently detected in human breast biopsy samples (Park et al, 2002). Clinical trials not only demonstrate the potential of MAGE-based vaccines against metastases, but also the need for further improvement (Thurner et al, 1999; Marchand et al, 2003; Kruit et al, 2005; Van Baren et al, 2005). In this study, we demonstrate that vaccination with Mage-b induces CD8 T-cell responses at young but not old age, which correlated with a stronger protective effect on metastases at young than at old age. These results imply that strategies for cancer vaccination against breast and possibly other cancers should be tailored to older age.

\section{MATERIALS AND METHODS}

\section{Mice}

BALB/c mice aged 3 and 20 months were obtained from the Harlan/National Institute of Aging Laboratories (Wilmington, MA, USA) and were maintained in the animal husbandry facility of the University of Texas Health Science Center San Antonio, according to the Association and Accreditation of Laboratory Animal Care guidelines. The mean lifespan of female $\mathrm{Balb} / \mathrm{C}$ mice is $25.5 \pm 4.6$ months (Anisimov, 2001).

\section{Plasmids}

The mouse Mage-b DNA plasmid (pcDNA3.1-Mage-b/V5) has been described previously (Sypniewska et al, 2005). The mouse granulocyte macrophage-colony stimulating factor (GM-CSF) plasmid (CMV1-GM-CSF) was kindly provided by Dr Stephen Johnston (The Center for Innovations in Medicine, The Biodesign Institute at Arizona State University) (Chambers and Johnston, 2003). The Listeria monocytogenes (LM)-based vaccine, expressing a fragment of Mage-b DNA (position: 311-660) as fusion protein with ListeriolysinO (LLO), designated as LM-LLO-Mage- $b_{311-660}$, has been described previously (Kim et al, 2008). The LM-LLO used in this study is attenuated, that is, the coding region for the C-terminal part of the LLO (cytolytic domain that binds cholesterol in the membranes) protein has been deleted. Mutations have been introduced into the prfA gene (expressed by the pGG34 vector), which reduced the pathogenicity of LM (Singh et al, 2005).

\section{Cells and cell culture}

The metastatic 4T1 cell line was derived from a spontaneous mammary carcinoma in a BALB/c mouse (Aslakson and Miller, 1992). 4TO7 and 64pT cell lines were derived from a spontaneous mammary carcinoma in a BALB/cfC3H mouse (Rak et al, 1992). A sub-line of $4 \mathrm{TO} 7$ has been developed in our laboratory $(4 \mathrm{TO} \mathrm{cg}$ ) and is metastatic as well (Sypniewska et al, 2005). All mouse mammary tumour cell lines were cultured in Dulbecco's modified Eagle's medium (DMEM) supplemented with $10 \%$ fetal bovine serum (FBS), $1 \mathrm{mM}$ mixed non-essential amino acids, $2 \mathrm{mM}$ L-glutamine, insulin (0.5 HSP Units per $\mathrm{ml}$ ), penicillin (100 Units per $\mathrm{ml})$, and streptomycin $\left(100 \mu \mathrm{g} \mathrm{ml}^{-1}\right)$.

\section{Breast tumours and metastases}

Breast tumours and metastases were generated in $\mathrm{BALB} / \mathrm{c}$ mice by the injection of $10^{5}$ cells of mouse mammary tumour cell line $4 \mathrm{TO} 7 \mathrm{cg}$ or $4 \mathrm{~T} 1$ into a mammary fat pad as described previously (Sypniewska et al, 2005; Gravekamp et al, 2008). Primary tumours were detected by palpation within 1-2 weeks in live mice. Twentytwo days after injection of the tumour cell line, mice were killed, weighed, and necropsied to evaluate the presence and frequency of metastases, as well as to determine the weight and size of primary tumours. $4 \mathrm{TO} 7 \mathrm{cg}$ is mildly metastastic with 2-20 metastases per mouse (Sypniewska et al, 2005). The $4 \mathrm{~T} 1$ cell line used in this study is highly aggressive with 5-300 metastases per mouse. Primary tumours extend to the chest cavity lining and metastasise predominantly to the mesenteric LNs (MLNs), and less frequently to the diaphragm, portal liver, and surface of the spleen and kidneys (Kim et al, 2008). Metastases were visible to the naked eye as nodules. The total number of metastases per mouse was determined. Normal and tumour tissues were collected aseptically and kept at $-80^{\circ} \mathrm{C}$, or fixed in $10 \%$ zinc solution for $48 \mathrm{~h}$ and kept in $70 \%$ ethanol, until use.

\section{RT-PCR and Southern blotting}

RNA was isolated using Trizol according to the manufacturer's instructions (Life Technologies, Carlsbad, CA, USA). Conversion of $1 \mu \mathrm{g}$ mRNA into cDNA was carried out using the Superscript Pre-amplification System (Life Technologies). Subsequently, $10 \mu \mathrm{l}$ of cDNA was amplified by hot start PCR (Platinum PCR SuperMix, Life Technologies) $\left(40\right.$ cycles at $94{ }^{\circ} \mathrm{C}$ for $30 \mathrm{~s}, 50{ }^{\circ} \mathrm{C}$ for $30 \mathrm{~s}, 72{ }^{\circ} \mathrm{C}$ for $2 \mathrm{~min}$ ) in a thermocycler from Perkin-Elmer (Norwalk, CT, USA). The primers used for the detection of Mage-b and $\beta$-actin (internal control for RNA quality) have been described previously (Sypniewska et al, 2005). The RT-PCR products were separated in an ethidium-bromide-stained agarose gel, transferred to an Immobilon- $\mathrm{N}^{+}$membrane (Amersham, Buckinghamshire, England), and hybridised with a chemiluminescence-labelled, sequence-verified 993-bp Mage-specific probe (AY196960) according to the manufacturer's instructions (enhanced chemiluminescence; Amersham).

\section{Immunisation and tumour challenge}

For both mouse tumour models, that is, $4 \mathrm{TO} 7 \mathrm{cg}$ and $4 \mathrm{~T} 1$, different immunisation protocols were used. Using the 4TO7cg model, Balb/ $\mathrm{C}$ mice were immunised as described previously (Sypniewska et al, 2005) and outlined in Figure 1A. Briefly, mice were immunised intramuscularly in both quadricepses at days 0 and 21 with $100 \mu \mathrm{l}$ of pyrogen-free saline containing $50 \mu \mathrm{g}$ of the Mage-b1/2 DNA vaccine (pcDNA3.1/Mage-b1/2-V5) or the control vector (pcDNA3.1/V5 or pcDNA3.1-LacZ/V5), or with $100 \mu$ l saline only. Two weeks after the last immunisation, mice were injected with $10^{5}$ $4 \mathrm{TO} 7 \mathrm{cg}$ tumour cells into a mammary fat pad. Four weeks after tumour challenge, the mice were killed and analysed for the frequency and location of metastases, and for the size of the primary tumours. Using the $4 \mathrm{~T} 1$ model, Balb/C mice were immunised as described previously (Gravekamp et al, 2008) and outlined in Figure 1B. Briefly, mice were injected with $1 \mathrm{ml}$ of $2.9 \%$ (w/v) TGB (Brewer thioglycollate broth B2551, Sigma-Aldrich, St Louis, MO, USA) into the peritoneal cavity to recruit professional antigen-presenting cells (APCs), that is, macrophages, to the peritoneal cavity (Yasuda et al, 2004). Four days later, they were immunised intraperitoneally with $100 \mu \mathrm{g}$ of Mage-b (pcDNA3.1Mage-b) or with $100 \mu \mathrm{g}$ of the control vector (pcDNA3.1), or saline. To improve the processing and presentation of the vaccine antigen, the vaccine and control vectors were mixed with $100 \mu \mathrm{g}$ of a plasmid-secreting GM-CSF. Granulocyte macrophage-colony stimulating factor plasmid DNA of $100 \mu \mathrm{g}$ was also added to the 
A

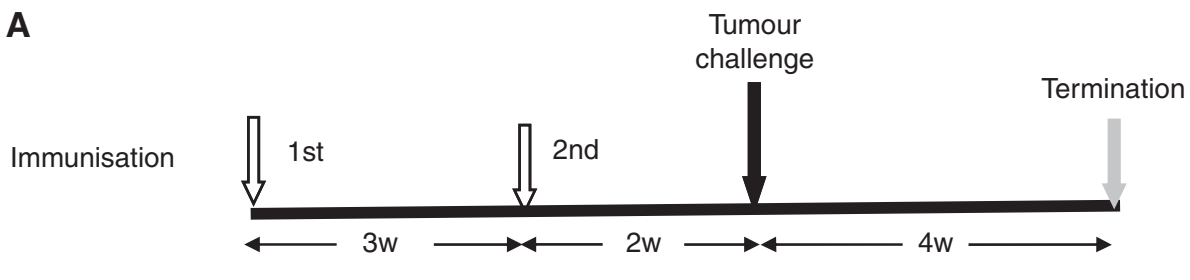

B

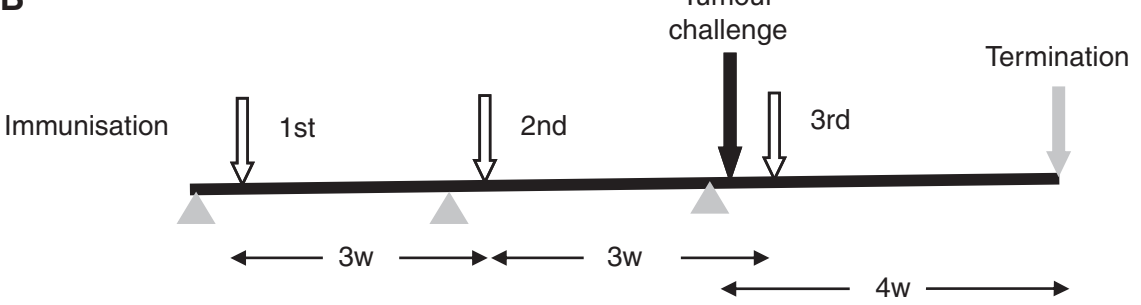

C

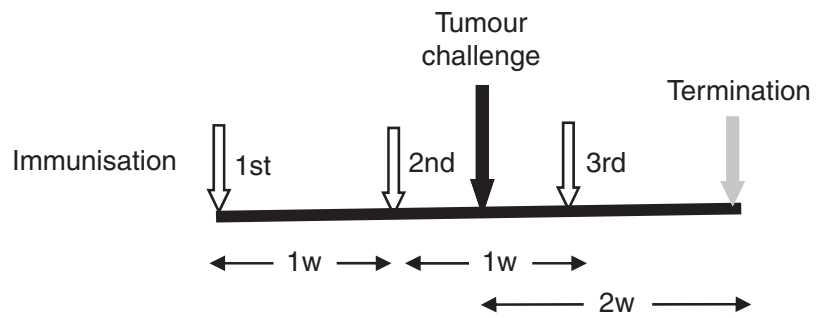

Figure I Schematic depiction of immunisations in $4 \mathrm{TO} \mathrm{cg}$ and $4 \mathrm{TI}$ mice. (A) $4 \mathrm{TO} \mathrm{cg}$ mice were twice immunised intramuscularly (im) with pcDNA3. I-Mage-b, pCDNA3.I, or with saline at days I and 2I. Two weeks after the last immunisation, mice were injected with $10^{5} 4 T O 7 \mathrm{cg}$ tumour cells into a mammary fat pad. Four weeks later, mice were killed and analysed. (B) 4TI mice were immunised intraperitoneally (ip) with pcDNA3. I-Mage-b + GM-CSF, pCDNA3.I + GM-CSF, or saline + GM-CSF at days I, 2I, and 42. All mice of the 4TI model received thioglycollate broth (TGB) ip 4 days before each immunisation (grey short arrow). At day 39, mice were injected with $10^{5} 4 \mathrm{TI}$ tumour cells into a mammary fat pad. Four weeks later, they were killed and analysed. (C) BALB/c mice were immunised thrice intraperitoneally with $0.1 \times L_{50}\left(10^{7} \mathrm{CFU}\right)$ of Listeria-based Mage- $b_{311-660}$ vaccine, $0.1 \times L D_{50}$ of LM-LLO vector control, or with saline, using I-week time intervals. Four days after the second immunisation, mice were injected with $10^{5} 4 T I$ tumour cells in a mammary fat pad. Two weeks after tumour challenge, mice were killed and analysed. Young mice were 3 months of age, and old mice 20 months.

saline group. Three and six weeks later, an identical second immunisation was performed. For tumour induction, mice were injected with $10^{5} 4 \mathrm{~T} 1$ tumour cells into a mammary fat pad 2 weeks after the second immunisation. Primary tumours were palpable about 8 - 10 days after tumour cell injection. Twenty-two days after tumour challenge, the mice were killed and analysed for tumour size, frequency, and location of metastases.

To determine the efficacy of the LM-LLO-Mage- $b_{311-660}$ vaccine, $\mathrm{Balb} / \mathrm{C}$ mice were immunised intraperitoneally (thrice; 1-week time interval) with $0.1 \times \mathrm{LD}_{50}\left(10^{7} \mathrm{CFU}\right)$ of the vaccine, $0.1 \times \mathrm{LD}_{50}$ of the control vector (LM-LLO), or with saline as described previously (Kim et al, 2008) and outlined in Figure 1C. For tumour induction, mice were injected with $10^{5} 4 \mathrm{~T} 1$ tumour cells into a mammary fat pad 4 days after the second immunisation. Fourteen days after tumour challenge, the mice were killed and analysed for tumour size, frequency and location of metastases.

\section{Re-stimulation of the spleen and LN cells in vitro}

Re-stimulation of cells from the spleen or draining LNs of mice that were vaccinated with pcDNA3.1-Mage-b was performed as described previously (Sypniewska et al, 2005). Briefly, spleen cells $\left(5 \times 10^{6} \mathrm{ml}\right.$ per well $)$ of vaccinated and control mice were restimulated by transient transfection with $0.5 \mu \mathrm{g}$ of Mage-b DNA using Lipofectamine plus (Invitrogen, Carlsbad, CA, USA) in 24 cluster-well plates. Cells from draining LNs of vaccinated and control mice were re-stimulated with $\gamma$-irradiated $(40 \mathrm{~Gy}) 64 \mathrm{pT}$ tumour cells $\left(0.5 \times 10^{6} \mathrm{LN}\right.$ cells per ml and $2 \times 10^{5}$ or $5 \times 10^{4} 64 \mathrm{pT}$ tumour cells per $\mathrm{ml}$ ). All re-stimulation assays were performed in DMEM, containing 10\% FBS. For determining interleukin (IL)-2 and interferon (IFN) $\gamma$ levels, supernatants were tested by quantitative enzyme-linked immunosorbent assay (ELISA) 24 and $72 \mathrm{~h}$ after re-stimulation, respectively. Quantitative ELISA was performed according to the manufacturer's instructions (Pharmingen, San Diego, CA, USA).

Re-stimulation of spleen cells of mice that were vaccinated with LM-LLO-Mage- $b_{311-660}$ was performed as described previously (Kim et al, 2008). Briefly, $2 \times 10^{5}$ spleen cells were re-stimulated in microtitre wells with $5 \times 10^{4}$ autologous bone marrow (BM) cells (transfected with pcDNA3.1-Mage-b plasmid DNA and pCMVGM-CSF plasmid DNA; $1 \mu \mathrm{g}$ of each plasmid DNA per $5 \times 10^{6} \mathrm{BM}$ cells), using the Nucleofector kit of AMAXA (Gaithersburg, MD, USA). Two days later, the frequency of IFN $\gamma$-producing cells was determined by ELISPOT for both re-stimulation assays according to standard protocols (Pharmingen), using an ELISPOT reader (CTL Immunospot S4 Analyzer, Cellular Technology Ltd, Cleveland, OH, USA). Spleen cells were depleted for CD8 T cells using magnetic bead depletion techniques according to the manufacturer's instructions (Miltenyi Biotec Inc, Auburn, CA, USA). Fluorescence-activated cell sorter (FACS) analysis demonstrated that $\geqslant 90 \%$ of all CD8 $\mathrm{T}$ cells were depleted.

\section{FACS analysis of spleen cells}

Spleen cells of young and old Mage-b-vaccinated and control mice bearing 4T1 tumours (15-20 mice per group) were pooled and analysed for the production of intracellular IFN $\gamma$, without in vitro re-stimulation. CD8 and CD4 T cells were analysed, as well as macrophages (anti-Mac3), natural killer (NK) cells (anti-CD49b), and B cells (anti-CD19). Analyses were carried out with non-gated 


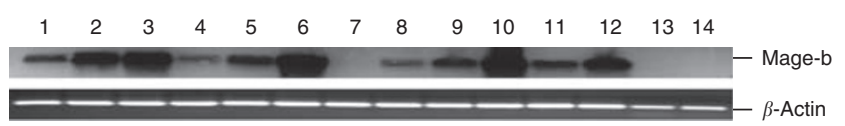

Figure 2 Expression levels of Mage- $b$ in metastases and primary tumours of the 4TI model at old age. The Mage-b-specific RT-PCR products of $632 \mathrm{bp}$ were detected by Southern blotting using a DNA probe encoding Mage-b. $\beta$-actin was used as RNA control for each sample. The lanes were loaded as follows: lanes I and 2, 4TI primary tumours; lanes 3 and 4, metastases mesenteric lymph nodes (LNs); lanes 5 and 6 , metastases liver; lanes 7 and 8 , metastases spleen; lanes 9 and 10 , metastases liver; lanes II and 12, metastases diaphragm; and lanes 13 and 14, normal breast. Tumour and normal tissues were randomly analysed from different mice $(n=5)$. Two representative examples of each tissue are shown in this figure.

cell populations (10000 cells per sample), and isotype-matched controls (CD8 (IgG2a), CD4 (IgG2b), Mac3 (IgG1), CD49b (IgG), and CD19 (IgG2a)) were used in each sample. Samples were analysed by the Flow Cytometry Core of the Cancer Therapy and Research Center (San Antonio, TX, USA) using a FACS (Calibur, BD Biosciences, San Jose, CA, USA). All antibodies were purchased from Pharmingen.

\section{RESULTS}

\section{Expression of Mage-b in metastases and tumours at old age}

In a previous study, we showed that Mage-b is highly expressed in 4TO7cg metastases and tumours in young and old mice (Gravekamp et al, 2004). We have also shown that Mage-b is highly expressed in $4 \mathrm{~T} 1$ metastases and tumours of young mice (Gravekamp et al, 2008). To confirm that Mage-b is also expressed in the $4 \mathrm{~T} 1$ metastases and primary tumours of old mice $(n=5$ mice), we randomly analysed tissues of 4T1 metastases (MLN, diaphragm, liver, spleen, and kidneys), primary tumours, and several normal tissues by RT-PCR and Southern blotting. As expected, all primary tumours and metastases expressed Mage-b, except one metastasis present on the surface of the spleen, which may have lost Mage-b expression as $\beta$-actin was highly expressed (Figure 2). In none of the normal tissues could Mage-b transcripts be detected.

\section{Effect of vaccination on $4 \mathrm{TO} \mathrm{cg}$ and $4 \mathrm{~T} 1$ metastases and primary tumours at young and old age}

Before the vaccine studies, we first analysed whether ageing had an effect on the growth of metastases and primary tumours in the two syngeneic metastatic mouse breast tumour models, $4 \mathrm{TO} 7 \mathrm{cg}$ and $4 \mathrm{~T} 1$. Some effect of ageing was observed in the $4 \mathrm{TO} 7 \mathrm{cg}$ model, but this was not significant. Although primary tumours were somewhat smaller in old than in young mice, the number of metastases was somewhat higher in old than in young mice (saline groups of Figure $3 \mathrm{~A}-\mathrm{D})$. We cannot exclude the possibility that the somewhat higher number of $4 \mathrm{TO} 7 \mathrm{cg}$ metastases at old compared with young age is due to age-related spontaneous tumours in the lungs and peritoneal cavity. These spontaneous tumours also express Mage-b (unpublished results). Age-related effects on the growth of $4 \mathrm{TO} 7 \mathrm{cg}$ tumours and metastases have also been extensively analysed in a previous study (Gravekamp et al, 2004).

In contrast to $4 \mathrm{TO} 7 \mathrm{cg}$, a dramatic effect of ageing was observed in the $4 \mathrm{~T} 1$ model. The number of metastases (Mann-Whitney $P=0.0492$ ) was significantly lower and tumour growth (Mann - Whitney $P<0.0001$ ) was less aggressive and significantly lower in old than in young mice of the 4T1 model (saline groups of Figure $3 \mathrm{E}-\mathrm{H}$ ). Slower progression of tumours in old hosts has also been observed in other animal models, such as a B16 melanoma model (Ershler, 1984), an EMT6 lung tumour model (Rockwell, 1981), and in an AKR lymphoma model (Itzthaki et al, 2000).

Vaccination of Mage-b (pcDNA3.1-Mage-b) was first tested in the less-aggressive $4 \mathrm{TO} \mathrm{cg}$ model (number of metastases varies between $2-20$ ) at young and old age. At young age, a significant effect of vaccination on metastases was observed in the Mage-b group compared with both control groups (Figure 3A), whereas at old age, the effect was less robust and no significant differences were observed between vaccinated and control groups (Figure 3B). The effect of Mage-b vaccination on primary tumours was not significant at both ages (Figure $3 \mathrm{C}$ and D).

After testing Mage-b DNA in the relatively mild metastatic breast tumour model $4 \mathrm{TO} 7 \mathrm{cg}$, we repeated the vaccine study in the highly aggressive 4T1 model. However, in this aggressive model (number of metastases varies between 5-300), the vaccine had initially little effect on metastases (unpublished results). Therefore, we improved the vaccination protocol by adding plasmid DNAsecreting GM-CSF to the Mage-b DNA vaccine, aiming to improve the activation of APCs, such as macrophages. In addition, we recruited APCs more efficiently into the peritoneal cavity by the injection of thioglycollate broth (TGB) before each vaccination, aiming to improve subsequent DNA uptake. At young age, a significant effect of vaccination with Mage-b and GM-CSF on metastases was observed (Figure 3E). A similar protective effect was observed at old age, although it was considerably less robust (Figure $3 \mathrm{~F}$ ). We also determined the sizes of primary 4T1 tumours after dissecting them from killed mice. At both ages, the average weight of primary tumours was significantly lower in vaccinated mice compared with the control groups (Figure $3 \mathrm{G}$ and $\mathrm{H}$ ).

Next, to further improve DNA uptake in vivo and the subsequent in vivo efficacy of Mage-b vaccination, we used an attenuated LM-based vaccine, expressing a Mage-b fragment (nucleotide position: $311-660$ ) as a fusion protein with LLO (Kim et al, 2008). Listeria monocytogenes delivers the vaccine antigen with very high efficiency into APC, such as monocytes and macrophages (Paterson and Maciag, 2005). Using this vaccine, a dramatic effect was observed on metastases at young age (Figure 3I), with a less robust but still significant effect at old age (Figure 3J). However, Mage-b vaccination did not reduce the growth of $4 \mathrm{~T} 1$ primary tumours at both ages (Figure $3 \mathrm{~K}$ and $\mathrm{L}$ ).

\section{Mage-b-specific immune responses in vitro at young and old age in the $4 \mathrm{TO} \mathrm{cg}$ and $4 \mathrm{~T} 1$ model}

To determine whether Mage-b-specific immune responses correlated with vaccine efficacy (effect of vaccine on metastases and tumours), we analysed pcDNA3.1-Mage-b-induced immune responses in the spleen and draining LNs of tumour-bearing mice at young and old age. Cells were re-stimulated with Mage-b DNA or with syngeneic $64 \mathrm{pT}$ tumour cells, highly expressing Mage-b. At young age, a strong increase in the levels of IL-2 and IFN $\gamma$ was observed in the vaccine group, compared with the control groups of the 4TO7cg model (Figure $4 \mathrm{~A}$ and $\mathrm{B}$ ). However, at old age, the levels of IL-2 and IFN $\gamma$ were almost undetectable (Figure 4A and B). Similar results were obtained with the $4 \mathrm{~T} 1$ model but Mage-bspecific immune responses were weaker in the $4 \mathrm{~T} 1$ than in the 4 TO7cg model at young age (Figure $4 \mathrm{C}$ and D). Although IL-2 and IFN $\gamma$ levels were significantly higher in the Mage-b than in the control groups for both models (at young age), the control groups showed immune responses to Mage-b as well. This may be because the spleens and LNs of all groups were isolated from mice with tumours and metastases, highly expressing Mage-b.

We also analysed Mage-b-specific immune responses in the spleens of young and old mice vaccinated with LM-LLO-Mage$b_{311-660}$. In this experiment, spleen cells of LM-LLO-Mage- $b_{311-660^{-}}$ vaccinated or control mice were re-stimulated with $\mathrm{BM}$ cells transfected with pcDNA3.1-Mage-b and pCMV1-GM-CSF. Although strong CD8 responses to Mage-b were observed at 
young age, as shown by the reduction in the number of IFN $\gamma$ producing cells (IL-2 is not produced) after the depletion of CD8 T cells, at old age CD8 T-cell responses were completely absent (Figure 4E). In summary, the results of these studies demonstrate that Mage-b-specific CD8 T-cell responses can be induced by vaccination with Mage-b DNA at young but not old age.

\section{Mage-b-specific immune responses in vivo at young and old age in the 4T1 model}

To analyse Mage-b-specific immune responses at young and old age in more detail in the 4T1 model, CD8 T cells, CD4 T cells, macrophages, NK cells, and B cells in the spleens of Mage-bvaccinated and control mice were analysed for the production of intracellular IFN $\gamma$ (Figure 5). To analyse Mage-b-specific immune responses directly in vivo, spleen cells were analysed without in vitro re-stimulation. At young age, an increase in the percentage of IFN $\gamma$-producing CD8 T cells was observed in Mage-b-vaccinated mice compared with both control groups, whereas at old age, IFN $\gamma$-producing CD8 $\mathrm{T}$ cells were almost undetectable. The percentage of IFN $\gamma$-producing CD4 T cells was low or undetectable in vaccinated or control mice at young age, but decreased in the control vector and in Mage-b-vaccinated mice compared with the saline control group at old age. The percentage of IFN $\gamma$-producing macrophages and NK cells increased moderately in Mage-b- vaccinated compared with control mice at old age and was not detectable at young age. The percentage of IFN $\gamma$-producing B cells decreased in Mage-b-vaccinated compared with control mice at young age, but was low and did not alter at old age.

\section{DISCUSSION}

Elderly individuals react less efficiently to vaccines than do adults, mainly because of T-cell unresponsiveness. In this study, we analysed whether cancer vaccination was more effective in young than in old mice with metastatic breast cancer. Various parameters were compared, such as (1) the growth of metastases and primary tumours in mice without vaccination to determine the age-related effect on cancer, (2) in vivo efficacy of Mage-b vaccination, and (3) CD8 T-cell responses induced by vaccination with Mage-b DNA. A mild $(4 \mathrm{TO} 7 \mathrm{cg})$ and a highly aggressive (4T1) metastatic mouse tumour models were used. Overall, the effect of vaccination on the growth of metastases and tumours was more robust at young than at old age. However, differences in vaccine efficacy were found between the two models. In the mild $4 \mathrm{TO} 7 \mathrm{cg}$ model, a significant effect of vaccination with pcDNA3.1-Mage-b on metastases was only observed at young age, whereas in the highly aggressive 4T1 model, a strong effect was found on metastases and primary tumours at both ages, although the effect was more robust at young than at old age.
A

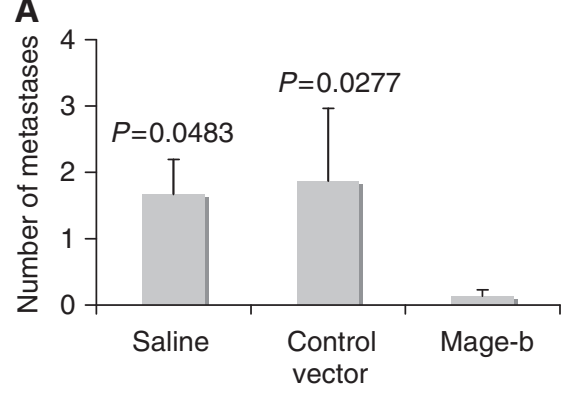

Young mice (4TO7cg)

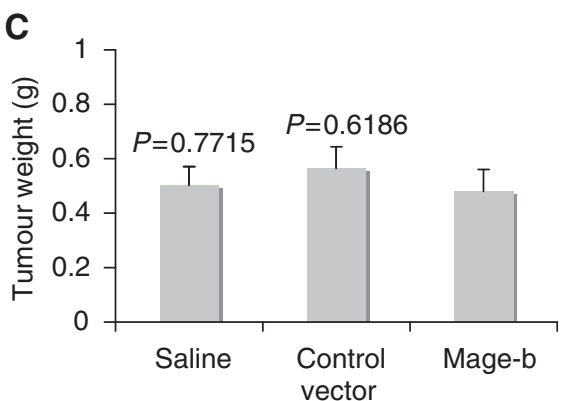

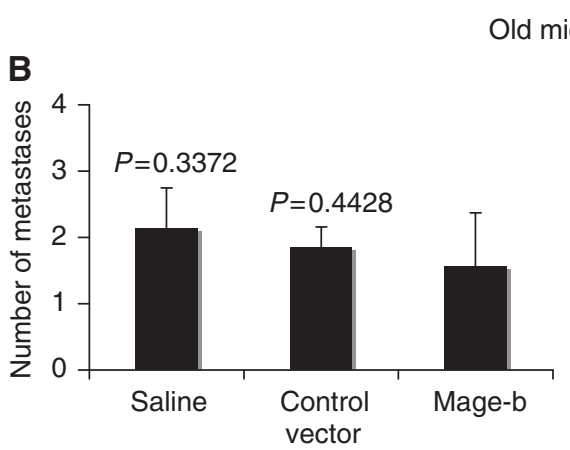

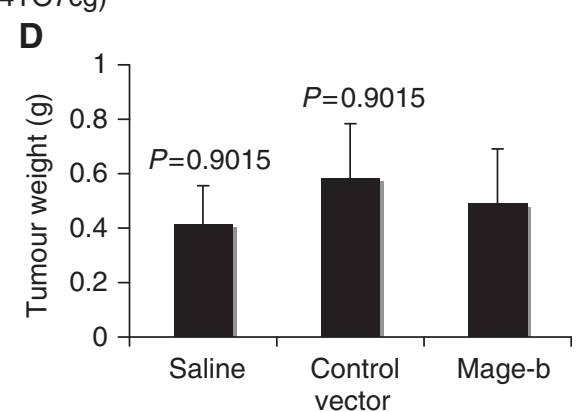

Figure 3 The effect of Mage-b vaccination on metastases and primary tumours at young and old age in 4TO7cg and 4TI models. The effect of vaccination with pcDNA3. I-Mage-b was measured on the growth of metastases and primary tumours of the 4TO7cg model (A-D). Young (3 months) and old (20 months) mice were immunised and challenged with 4TO7cg tumour cells as described in Figure IA. The number of metastases per mouse was determined in young (panel A) and old (panel B) mice. Furthermore, tumour weight was determined in young (panel C) and old (panel D) mice. At young age $n=15$ mice per group, and at old age $n=7$ mice per group. Results were averaged per group and subjected to statistical analysis using the Mann-Whitney test $(P<0.05$ is significant). This experiment was performed once. The effect of Mage-b vaccination was also measured on the growth of metastases and primary tumours of the 4TI model $(\mathbf{E}-\mathbf{H})$. Young and old mice were immunised and challenged with 4TI tumour cells as described in Figure IB. The number of metastases per mouse was determined in young (panel E) and old (panel F) mice. Furthermore, tumour weight was determined in young (panel G) and old (panel H) mice. The results shown in this study are the average of three independent experiments, and subjected to statistical analysis (Mann-Whitney $P<0.05$ is significant). $n=5-10$ mice per group. Each triangle represents one mouse. In addition, the effect of vaccination with LM-LLO-Mage- $b_{3} \mid 1-660$ was measured on the growth of metastases and primary tumours of the 4TI model at young and old (I-L) age. Young and old mice were immunised and challenged with 4TI tumour cells as described in Figure IC. The number of metastases per mouse was determined in young (panel I) and old (panel I) mice. Moreover, tumour weight was determined in young (panel K) and old (panel L) mice. Results were averaged per group and subjected to statistical analysis (Mann-Whitney $P<0.05$ is significant). In this experiment, $n=5$ mice per group, and the experiment was performed once. In all figures, the results in the Mage-b group were compared with those in both control groups; error bars represent s.e.m. 

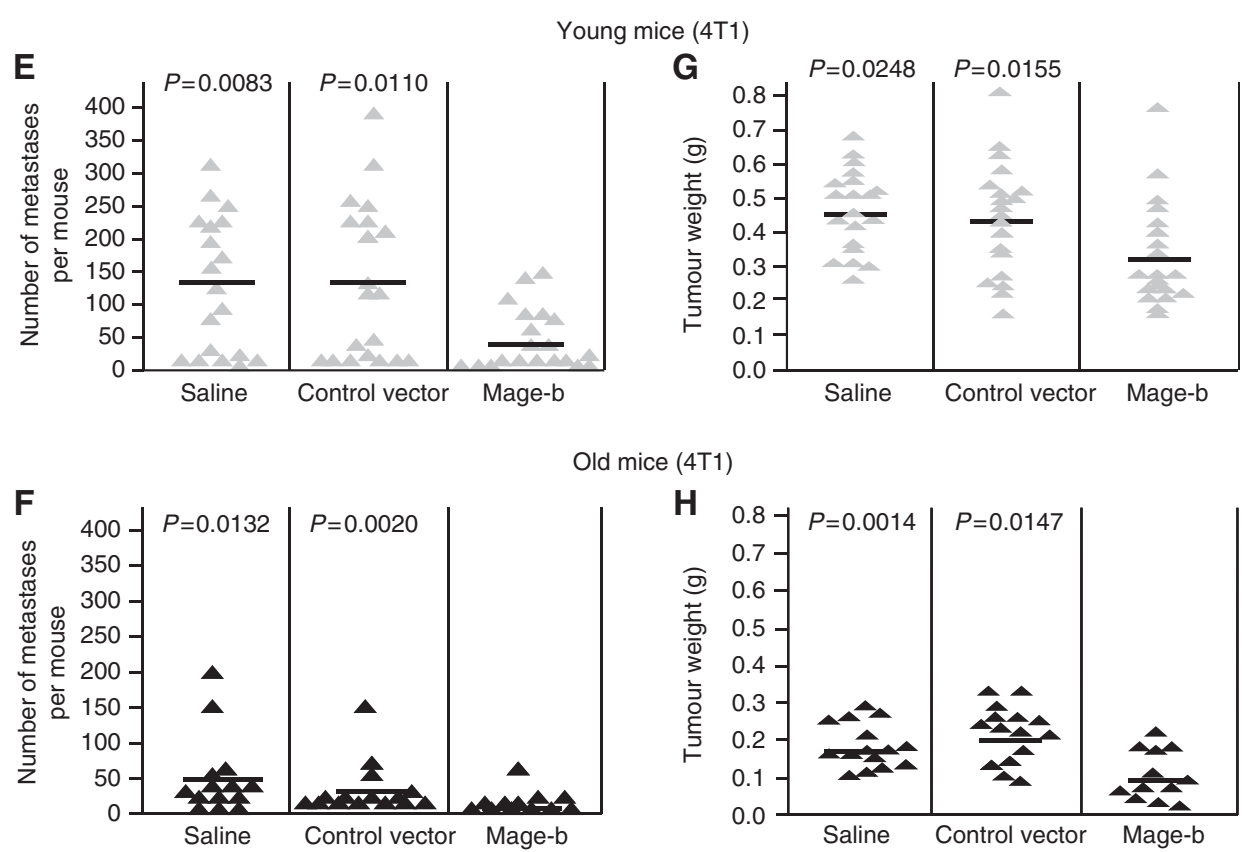

Old mice (4T1)
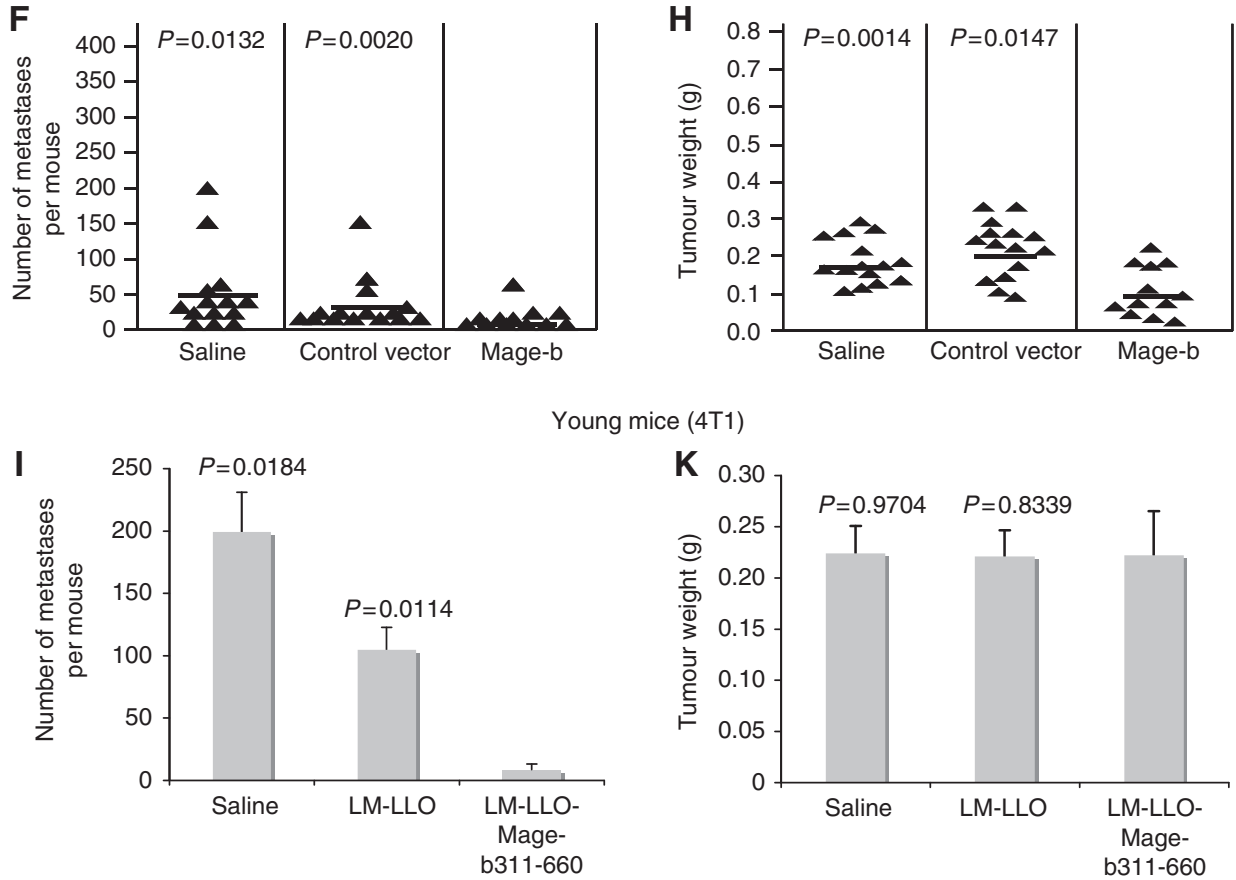

Old mice (4T1)
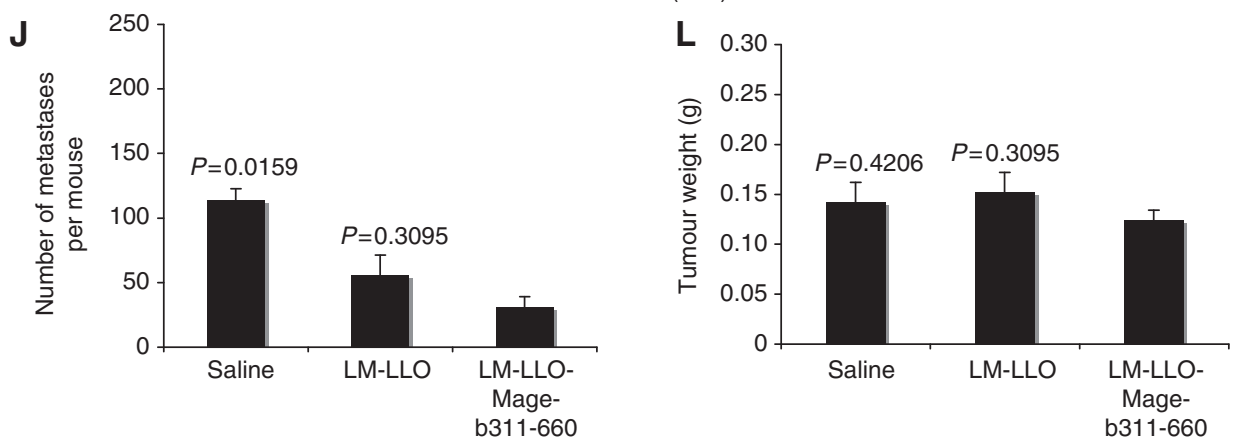

Figure 3 Continued.

Various factors may contribute to the difference in vaccine efficacy between the two models. For instance, in the 4T1 model, but not in the $4 \mathrm{TO} 7 \mathrm{cg}$ model, GM-CSF and TGB were added to the pcDNA3.1-Mage-b vaccine. Both agents highly activate macrophages (Yasuda et al, 2004; Shi et al, 2006), which may have contributed to the reduction in tumour growth at young and old age. Tumour-associated macrophages (TAMs) present within the tumour have a crucial role in the suppression and activation of the immune system in cancer patients. Macrophages may secrete factors or lymphokines such as IL-6, TGF $\beta$, IL-10, or prostaglandine $\mathrm{E}(\mathrm{PGE})_{2}$, which inhibit T-cell responses, or macrophages may secrete IFN $\gamma$ or IL-12, which activates T-cell responses (for a review, see Gravekamp et al, 2009). However, TAM can also become tumouricidal when producing IFN $\gamma$ and TNF $\alpha$ (BaronBodo et al, 2005; Ouyang et al, 2006), or promote angiogenesis by secreting IL-8, migration inhibitory factor, or vascular endothelial growth factor (Shih et al, 2006). Therefore, control of TAM is an important consideration for cancer immunotherapy.

Granulocyte macrophage-colony stimulating factor and TGB may not be the only factors involved in the stronger effect of vaccination with Mage-b in the 4T1 model compared with the 4 TO7cg model. Furthermore, ageing, especially in the 4T1 model, had an important role in the growth of metastases and primary tumours. A dramatic decrease in the growth of metastases and 
4TO7cg model
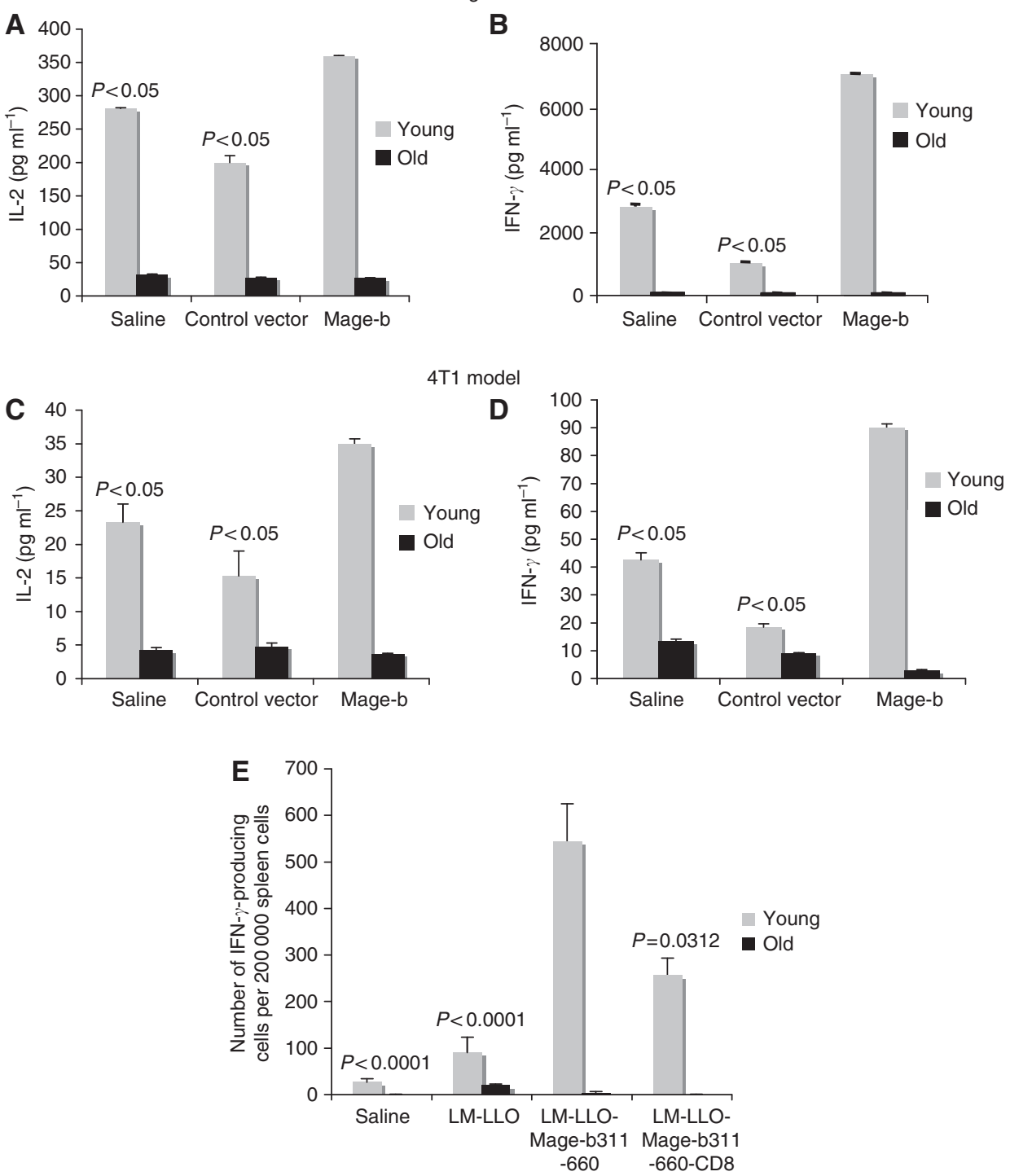

Figure 4 Mage-b-induced immune responses (in vitro) at young and old age in the 4TO7cg and 4TI model. Mage-b-induced immune responses were determined at young and old age. Mice were vaccinated (pcDNA3. I-Mage-b) and challenged with 4TO7cg or 4TI tumour cells, as shown in Figure IA or B, respectively. Cells from spleens were transfected with Mage-b DNA, and draining LNs were re-stimulated with syngeneic 64pT breast tumour cells, highly expressing Mage-b. The production of IL-2 by cells in the spleen ( $\mathbf{A}$ and $\mathbf{C}$ ) and of IFN $\gamma$ by cells in the draining lymph nodes (LNs) (B and $\mathbf{D})$ of vaccinated and control mice was determined by quantitative ELISA. Controls such as nonstimulated cells from spleens or draining LNs were negative (data not shown). All experiments were performed in triplicate and subjected to statistical analysis using the Tukey-Kramer Multiple Comparison test ( $P<0.05$ is significant). The cytokine levels produced in the Mage-b group were compared with those produced in the saline and vector control groups. At young age $n=10$ mice per group, and at old age $n=15$. Mice were also vaccinated with LM-LLO-Mage-b $311-660$ and challenged with 4TI tumour cells, as shown in Figure IC. Cells from spleens were re-stimulated with bone marrow cells transfected with pcDNA3. I-Mage-b and pCMVI -GM-CSF plasmid DNA. Two days later, Mage-bspecific immune responses were analysed by ELISPOT $(\mathbf{E})$. Involvement of Mage-b-specific CD8 T cells was determined by negative depletion, using magnetic beads with anti-CD8 antibodies. Controls such as BM cells transfected with pcDNA3.I-Mage-b or with pCMV-GM-CSF, and nontransfected BM cells were negative (data not shown). All experiments were performed in triplicate. $n=5$ mice per group, and were used once. Results were averaged and subjected to statistical analysis using the Mann-Whitney test $(P<0.05$ is significant). The number of IFN $\gamma$-producing cells in the Mage group was compared with that in the saline and vector control groups. In all figures, cells from spleens or draining LNs were pooled; error bars represent the s.e.m.

primary tumours of the saline group at old compared with young age was observed in the highly metastatic $4 \mathrm{~T} 1$ model, but was less pronounced and not significant in the mildly metastatic $4 \mathrm{TO} 7 \mathrm{cg}$ model. This could not be because of GM-CSF and TGB, as the dramatic age-related effect on the growth of metastases and primary tumours was also observed in the vaccine study with LMLLO-Mage- $b_{311-660}$, in which GM-CSF and TGB were not included.

If the in vivo efficacy of Mage-b vaccination is less robust in old than in young mice, is this because of decreased Mage-b-specific immune responses at old age? Three different methods were used to analyse Mage-b-specific immune responses in the spleens and LNs, namely quantitative ELISA, ELISPOT, and FACS. Only at young age could CD8 $\mathrm{T}$ cells be activated with Mage-b in the 4T1 model, and only at young age did IL-2 and IFN $\gamma$ increase significantly in the spleens and LNs of Mage-b-vaccinated compared with control mice in the $4 \mathrm{TO} 7 \mathrm{cg}$ model. Hence, this shows that vaccination with Mage-b DNA activates CD8 $\mathrm{T}$ cells at young but not at old age, which correlated with a significant effect on metastases at both ages, although the effect was less robust at old than at young age. The unresponsiveness of CD8 T cells to 

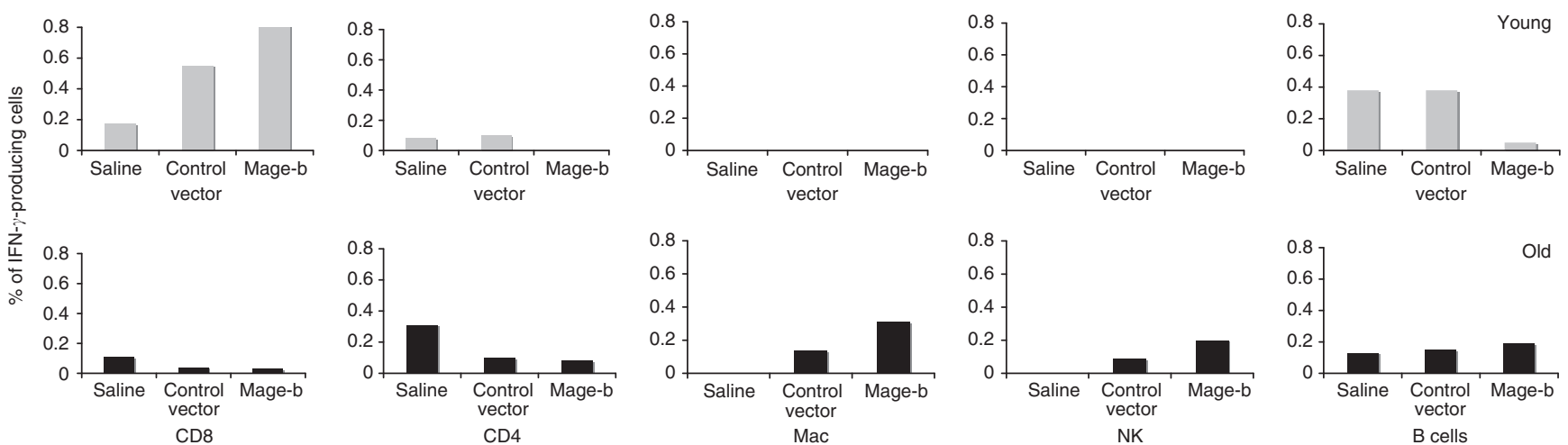

Figure 5 Mage-b-specific immune responses (in vivo) at young and old age in the 4TI model. Young and old mice were vaccinated, as shown in Figure IB. CD8 T cells, CD4 T cells, macrophages, NK cells, and B cells were analysed by fluorescence-activated cell sorter (FACS) for the production of intracellular IFN $\gamma$ without re-stimulation in vitro. Spleen cells of I5-20 mice in each group were pooled. Of each sample, 10000 spleen cells were analysed by FACS. The percentage of IFN $\gamma$-producing cells was determined for each cell type.

Mage-b vaccination at older age might be because of the lack of naive $\mathrm{T}$ cells, or poorly functioning $\mathrm{CD} 4 \mathrm{~T}$ cells at older age (George and Ritter, 1996; Grubeck-Loebenstein, 1997; Haynes et al, 2003).

Which immune cells or factors contributed to fewer metastases at older age is not clear yet. In preliminary studies with pcDNA3. 1 -Mage-b, we analysed macrophages and NK cells, as well as apoptotic pathways in metastases. We found that fewer metastases at old age correlated with lower expression levels of active caspase3 and a decrease in the expression levels of Fas, FasL, and TRAIL (data not shown). Although these results suggest that immune cells (perhaps macrophages) rather than tumour cells are responsible for the observed lower expression levels of active caspase-3, analysis of tumour-infiltrating immune cells and tumour cells, separately, will be necessary to determine the contribution of each cell type to the expression level of active caspase- 3 in metastases at old age.

Weak-to-moderate responses of macrophages and NK cells were observed in Mage-b-vaccinated compared with control mice at old age (Figure 5). These innate immune responses may have been studied too late after vaccination (4 weeks after the last vaccination) and could have been more robust at earlier time points. More research will be necessary to determine the role of macrophages and NK cells in cancer vaccination at older age.

From studies with LM-LLO-Mage- $b_{311-660}$, a possibility emerged that could provide an alternative explanation for the significant effect of vaccination on metastases in the absence of Mage-bspecific CD8 T-cell responses at old age. As recently discovered, Listeria bacteria infect and kill tumour cells without the need of Mage-b-specific CD8 T cells, resulting in the complete eradication of metastases and an almost complete eradication of primary tumours at young age (Kim et al, 2009). Therefore, in this study, the effect of LM-LLO-Mage- $b_{311-660}$ vaccination on metastases at old age (Figure 4E) may have been because of the Listeriainduced kill.

Thus far, all cancer vaccines in clinical trials are based on preclinical studies at young age. The results of this study and studies reported by others (Provinciali et al, 2003; Lustgarten et al, 2004; Sharma et al, 2006) demonstrate the importance of the age factor in cancer vaccination. However, these results also suggest that cancer vaccination is feasible at older age and that further improvement and tailoring to older age in preclinical animal models before human application is of crucial importance.

\section{ACKNOWLEDGEMENTS}

This work was supported by NIA Grant no. 1RO1 AG023096 and by the American Federation for Aging Research (AFAR) A000106. We thank Ilyssa Ramos and Denise Asafu-Adjei.

\section{REFERENCES}

Anisimov VN (2001) Life span extension and cancer risks: myths and reality. Exp Gerontol 36: 1101-1136

Aslakson CJ, Miller FR (1992) Selective events in the metastatic process defined by analysis of the sequential dissemination of subpopulations of a mouse mammary tumor. Cancer Res 52: 1399-1405

Baron-Bodo V, Doceur P, Levebre ML (2005) Anti-tumor properties of human-activated macrophages produced in large scale for clinical application. Immunobiology 210: 267-277

Chambers RS, Johnston SA (2003) High-level generation of polyclonal antibodies by genetic immunization. Nat Biotechnol 21: 1088-1092

Ershler WB (1984) The aggressiveness of neoplasms with age. Geriatrics 42: 99- 103

George AJT, Ritter MA (1996) Thymic involution with ageing: obsolescence or good housekeeping? Immunol Today 17: 267-272

Gravekamp C, Kim SH, Castro F (2009) Cancer vaccination: manipulation of immune responses at old age. Mech Ageing Dev 130: 65-75
Gravekamp C, Leal B, Denny A, Bahar R, Lampkin S, Castro F, Kim SH, Moore D, Reddick R (2008) In vivo responses to vaccination with Mage-b, GM-CSF and thioglycollate in a highly metastatic mouse breast tumor model, 4T1. Cancer Immunol Immunother 57: 1067 - 1077

Gravekamp C, Sypniewska R, Gauntt S, Tarangoo M, Price P, Reddick R (2004) Behavior of metastatic and nonmetastatic breast tumors in old mice. Exp Biol Med 229: 665-675

Grubeck-Loebenstein B (1997) Changes in the aging immune system. Biologicals 25: 205-208

Haynes L, Eaton SM, Burns EM, Randall TD, Swain SL (2003) CD4 T cell memory derived from young naïve cells functions well into old age, but memory generated from aged naïve cells functions poorly. Proc Natl Acad Soc 100: $15053-15058$

Itzthaki O, Skutelsky E, Kaptzan T (2000) Macrophage-recognized molecules of apoptotic cells are expressed at higher levels in the AKR lymphoma of aged compared to the young mice. Adv Exp Med Biol 479: 251-262 
Kim SH, Castro F, Gonzalez D, Maciag P, Paterson Y, Gravekamp C (2008) Mage-b delivered by recombinant Listeria monocytogenes is highly effective against breast cancer metastases. Br J Cancer 99: 741 - 749

Kim SH, Castro F, Gravekamp C (2009) High efficacy of a Listeria-based vaccine against metastatic breast cancer reveals a dual mode of action. Cancer Res 69: $5860-5866$

Kruit WH, van Ojik HH, Brichard VG, Escudier VG, Dorval T, Dreno B, Patel P, van Baren N, Avril MF, Piperno S, Khammari A, Stas M, Ritter G, Lethe B, Godelaine D, Brasseur F, Zhang Y, van der Bruggen P, Boon T, Eggermont AM, Marchand M (2005) Phase $\frac{1}{2}$ study of subcutaneous and intradermal immunization with a recombinant MAGE-3 protein in patients with detectable metastatic melanoma. Int J Cancer 117: 596-604

Lurquin C, De Smet C, Brasseur F, Muscatelli F, Martelange V, De Plaen E, Brasseur R, Monaco AP, Boon T (1997) Two members of the human MAGE-B gene family located in Xp21.3 are expressed in tumors of various histological origins. Genomics 46: $397-408$

Lustgarten J, Dominguez AL, Thomas M (2004) Aged mice develop protective antitumor responses with appropriate costimulation. I Immunol 173: 4510 - 4515

Marchand M, Punt CJ, Aamdal S, Escudier B, Kruit WH, Keilholz U, Hakansson L, van Baren N, Humblet Y, Mulders P, Avril MF, Eggermont AM, Scheibenbogen C, Uiters J, Wanders J, Delire M, Boon T, Stoter G (2003) Immunization of metastatic cancer patients with MAGE-3 protein combined with adjuvant SBAS-2: a clinical report. Eur J Cancer 39: 70 - 77

McElhaney JE, Meneilly GS, Lechelt KE, Bleackley RC (1994) Split-virus influenza vaccines: do they provide adequate immunity in the elderly? Gerontol 49: M37-M43

Pardal R, Clarke MF, Morrison SJ (2003) Applying the principles of stemcell biology to cancer. Nat Rev Cancer 3: 895-902

Park JW, Kwon TK, Kim IH, Sohn SS, Kim YS, Bae OS, Lee KS, Lee CS, Chang HK, Choe BK, Ahn SY, Jeon CH (2002) A new strategy for the diagnosis of MAGE-expressing cancers. J Immunol 79: 79-86

Paterson Y, Maciag PC (2005) Listeria-based vaccines for cancer treatment. Curr Opin Mol Ther 7: 454-460

Provinciali M, Smorlesi A, Donnini A, Bartozzi B, Amici A (2003) Low effectiveness of DNA vaccination against HER2/neu in aging. Vaccine 21: $843-848$

Quyang Q, Cicek G, Westendorp RGJ, Cools HJM, ven der Klis RJ, Remarque EJ (2000) Reduced IFN $\gamma$ production in elderly people following in vitro stimulation with influenza vaccine and endotoxin. Mech Ageing Dev 121: $131-137$

Ouyang GF, Saio M, Suwa T (2006) Interleukin-2 augmented activation of tumor-associated macrophage plays the main role in MHC class I in vivo induction in tumor cells that are MHC negative in vitro. Int J Oncol 28: $1201-1208$

Rak JW, McEachern D, Miller FR (1992) Sequential alteration of peanut agglutinin binding-glycoprotein expression during progression of murine mammary neoplasia. Br J Cancer 65: 641-648
Rockwell S (1981) Effect of host age on transplantation, growth and radiation response of EMT6 tumors. Cancer Res 41: 527-531

Scarth H, Cantin J, Levin M (2002) Clinical practice guidelines for the care and treatment of breast cancer: mastectomy or lumptectomy? The choice of operation for clinical stages I and II breast cancer (summary of 2002 update). CMAJ 167: $154-155$

Shi Y, Roberts AI, Das J, Xu G, Ren G, Zhang Y, Zhang L, Yuan ZR, Tan HS, Das G, Devadas S (2006) Granulocyte-macrophage-colony-stimulating factor (GM-CSF) and T-cell responses: what we do and don't know. Cell Res 16: $126-133$

Shih JY, Yuan A, Chen JJW, Yang PC (2006) Tumor-associated macrophage: its role in cancer invasion and metastasis. J Mol Cancer 2: $101-106$

Sharma S, Domiguez AL, Lusgarten J (2006) Aging affect the anti-tumor potential of dendritic cell vaccination, but it can be overcome by costimulation with anti-OX40 or anti-4-1BB. Exp Ger 41: 78-84

Singh R, Domineicki ME, Jaffee EM, Paterson Y (2005) Fusion of Listeriolysin $\mathrm{O}$ and delivery by Listeria monocytogenes enhances the immunogenicity of HER-2/neu and reveals subdominant epitopes in the FVB/N mouse. J Immunol 175: 3663-3673

Sypniewska RK, Hoflack L, Tarango M, Gauntt S, Leal BZ, Reddick RL, Gravekamp C (2005) Prevention of metastases with a Mage-b DNA vaccine in a mouse breast tumor model: potential for breast cancer therapy. Breast Cancer Res Treat 91: 19-28

Thurner B, Haendle I, Roder C, Deickmann D, Keikavoussi P, Jonuleit H, Bender A, Maczek C, Schreiner D, von den Driesch P, Brocker EB, Steinman RM, Enk A, Kampgen E, Schuler G (1999) Vaccination with Mage-3A1 peptide-pulsed mature monocyte-derived dendritic cells expands specific cytotoxic $\mathrm{T}$ cells and induces regression of some metastases in advanced Stage IV melanoma. J Exp Med 190: $1169-1178$

Van Baren N, Bonnet MC, Dreno B, Khammari A, Dorval T, PipernoNeumann S, Lienard D, Speiser D, Marchand M, Brichard VG, Escudier B, Negrier S, Dietrich PY, Maraninchi D, Osanto S, Meyer RG, Ritter G, Moingeon P, Tartaglia J, van der Bruggen P, Coelie PG, Boon T (2005) Tumoral and immunological response after vaccination of melanoma patients with ALVAC virus encoding MAGE antigens recognized by $\mathrm{T}$ cells. J Clin Oncol 23: $9008-9021$

Yasuda K, Kawano H, Yamane I, Ogawa Y, Yoshinaga T, Nishikawa M, Takakura Y (2004) Restricted cytokine production from mouse peritoneal macrophages in culture in spite of extensive uptake of plasmid DNA. Immunol 111: 282-290

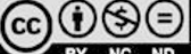

This work is licensed under the Creative Commons Attribution-NonCommercial-NoDerivs 3.0 License. To view a copy of this license, visit http://creativecommons.org/ licenses/by-nc-nd/3.0/. 